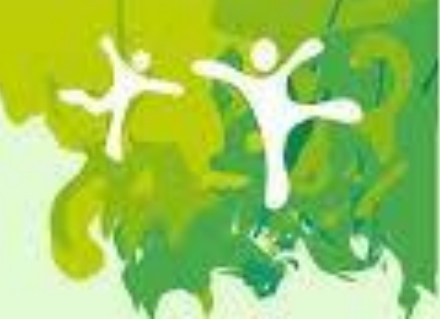

\title{
A COMPOSIÇAO CORPORAL DE PACIENTES COM SÍNDROME DE DOWN
}

\section{Pôster}

Autores deste trabalho:

Thiago Olivetti Artioli: Irmandade da Santa Casa de Misericórdia de São Paulo

Eduardo Witsmiszyn: Irmandade da Santa Casa de Misericórdia de São Paulo

Aleksandro Belo Ferreira: Irmandade da Santa Casa de Misericórdia de São Paulo

Carla Franchi Pinto: Irmandade da Santa Casa de Misericórdia de São Paulo

Área do Trabalho: Pediatria

Número de inscrição: 5246

Data da submissão:26/08/2016 às 17:03

\section{Justificativa}

A Síndrome de Down (SD) é a aneuploidia mais frequente na espécie humana. Crianças com SD possuem predisposição à obesidade, sendo avaliadas, como as crianças típicas, através do índice de massa corpórea (IMC). Todavia é sabido que o fenótipo destes indivíduos pode acarretar um viés no uso deste índice, o que pode comprometer a avaliação clínica e a elaboração de protocolos de atendimento para estes indivíduos.

\section{Objetivo(s)}

O presente estudo propõe a aferição da composição corporal em indivíduos atendidos no ambulatório multidisciplinar de orientação à síndrome de Down da Santa Casa de São Paulo (AMOR/SDSC) com o uso da técnica DXA, padrão ouro atual, para a comparação de seus valores com os encontrados em indivíduos não-portadores de SD.

\section{Método(s)}

Foram coletados dados de pacientes de maneira aleatória, atendidos no AMOR/SDSC, seus valores de IMC, e realização da aferição da composição corporal com a técnica DXA em máquina Lunar Prodigy Advance, com valores comparados às referências da literatura e analisados sob o teste de qui quadrado de proporções. 


\section{Resultado(s)}

Foram analisados 45 indivíduos, com prevalência de 58\% do sexo feminino, idade média de 11 anos e $35,5 \%$ de obesidade pelo Z-score do IMC. Desta população 75,5\% apresentaram valores percentuais de gordura corporal acima da referência, sendo que do subgrupo dos indivíduos com SD eutróficos pelo IMC 57,1\% apresentaram DXA alterado.

\section{Conclusão(ões)}

O IMC nos pacientes com SD apresenta correspondência com a composição corporal apenas nos indivíduos classificados como sobrepeso ou obeso pelo Z-score do IMC. Crianças com SD com IMC considerados sem alteração não apresentam correspondência estatística com o DXA, pois parcela significativa delas possuem porcentagem de gordura acima do esperado. Os dados permitem concluir que o IMC não é um instrumento adequado para inferir a composição corporal nas crianças com SD. Este estudo propõe que os protocolos de atendimento baseados nesse índice devam ser rediscutidos e novas propostas para avaliação metabólica nessa população são necessárias, especialmente naqueles considerados adequados no Z-score do IMC. 